\title{
Developmental Aspects of Maleic Acid-induced Inhibition of Sugar and Amino Acid Transport in the Rat Renal Tubule
}

\author{
KARL S. ROTH, DAVID R. GOLDMANN, AND STANTON SEGAL \\ Division of Biochemical Development and Molecular Diseases, Children's Hospital of Philadelphia, and the \\ Departments of Pediatrics and Medicine, Medical School of the University of Pennsylvania, Philadelphia, \\ Pennsylvania, USA
}

\section{Summary}

The transport of $\alpha$-aminoisobutyric acid and $\alpha$-methyl-D-glucoside by isolated renal tubules from Sprague-Dawley rats at different stages of development follows a separate age-dependent pattern for each substrate. The effects of $6 \mathrm{mM}$ maleic acid on transport processes differ for amino acids and sugars and become manifest at distinct points during development. Maximum inhibition by maleic acid occurs at a time subsequent to maturity of these transport systems. In an effort to explain these transport phenomena, the uptake and metabolism of ${ }^{14} \mathrm{C}$-labeled maleic acid by the newborn or adult renal tubule was studied, showing significant binding by the tubule membrane, penetration of the cell by diffusion, and no conversion to ${ }^{14} \mathrm{CO}_{2}$. Maleic acid has no demonstrable effect on the membrane-associated enzymes which are thought to play a role in the transport of small molecules.

\section{Speculation}

Although the mechanism by which maleic acid inhibits the transport of sugars and amino acids in the adult rat tubule preparation remains unexplained, it is clear that its effects are age-related and independent of the maturation of these transport systems. This observation is consistent with the delayed appearance of the Fanconi syndrome seen in human cystinosis, and suggests that the progressive tubular dysfunction in this syndrome and in the maleic acid model is secondary to genetically directed intracellular metabolic changes expressed during development.

The Fanconi syndrome is characterized by renal tubular dysfunction resulting in urinary findings including glycosuria and generalized aminoaciduria. This syndrome is seen in a variety of disorders including several inherited metabolic diseases, but remains poorly understood on a basic biochemical level. In one such disorder, cystinosis, the Fanconi syndrome appears between the ages of 6 months to 1 year, presumably a manifestation of cystine toxicity, and eventually leads to growth retardation and renal failure.

The biochemical basis of this tubular dysfunction has been explored by several investigators using experimental animals in which the Fanconi syndrome can be induced by the administration of maleic acid. This work has led to several hypotheses, including the possibilities that maleic acid may induce functional changes in the tubular cell by a direct effect on membrane constituents $(10,15)$ or on intracellular metabolic processes which in turn modulate changes in the influx and efflux of small molecules ( 1 , 17). None of the previous work, however, has investigated the in vitro effect of maleic acid on the tubule in relation to the development of transport processes from the newborn period through adulthood.

We have studied the development of sugar and amino acid transport in isolated tubules from rats of different ages with and without the presence of maleic acid. These transport processes show distinct patterns of development independent of their inhibition by maleic acid. In an effort to account for these observations, we studied the uptake of maleic acid by newborn and adult tubules and the effects of maleic acid on membrane-associated enzymes thought to be related to transport of small molecules.

\section{MATERIALS AND METHODS}

Gravid female Sprague-Dawley rats were obtained from Charles River Breeding Laboratories (Wilmington, MA) at 14 days of gestation and fed ad libitum on Purina chow until parturition. Pups were killed by decapitation within $72 \mathrm{hr}$ of age. Adult male Sprague-Dawley rats weighing 150-200 g were obtained from the same source and used for the preparation of isolated adult tubules. No differentiation with regard to sex was made with animals less than 21 days of age.

\section{PREPARATION OF TUBULES}

The kidneys were rapidly removed after killing the animals and placed in ice-cold Krebs-Ringer bicarbonate buffer (KRB) containing $10 \mathrm{mM}$ sodium acetate, $\mathrm{pH}$ 7.4. Cortical chips from 40-60 newborn rat kidneys were cut freehand with a scalpel, whereas cortical slices from the adult were made with a Stadie-Riggs microtome. In each case the cortical tissue was minced and placed into a $0.375 \%(\mathrm{w} / \mathrm{v})$ solution of collagenase (grade II; Worthington Biochemical Corp., Freehold, NJ) in KRB. Following a 45-min digestion, the tubules were washed in ice-cold $\mathrm{KRB}$ and centrifuged for $90 \mathrm{sec}$ at $40 \times g$ in an International UV model centrifuge. The washing procedure was repeated three times. Newborn tissue was filtered through two layers of nylon stocking, whereas adult tissue was filtered through three layers of surgical gauze. The resulting tubule suspensions were brought to the desired final volume with $\mathrm{KRB}$, and fetal calf serum $(1 \mathrm{ml} / 20 \mathrm{ml}$ of tubule suspension) was added to prevent clumping. Dilutions contained $10-12 \mathrm{mg}$ of tubule fragments $/ \mathrm{ml}$.

\section{UPTAKE STUDIES}

Uptake of ${ }^{14} \mathrm{C}$-labeled $\alpha$-aminoisobutyric acid, a nonmetabolized neutral amino acid analog, $\alpha$-methyl-D-glucoside, a nonmetabolized sugar analog, and maleic acid were studied in newborn and adult tubule preparations using a modification of the technique of Burg and Orloff (5), previously applied to studies of newborn and adult rat renal tubule fragments (20). Distribution ratios $(\mathrm{cpm} / \mathrm{ml}$ intracellular fluid to $\mathrm{cpm} / \mathrm{ml}$ medium) were calculated according to the method of Rosenberg, et al. (16) and the results expressed in a plot of the distribution ratio versus time of sampling. $\left[1-{ }^{14} \mathrm{C}\right] \alpha$-Aminoisobutyric acid $(5.0 \mathrm{mCi} / \mathrm{mmole})$ was obtained from New England Nuclear Corp., Boston, MA [U- $\left.{ }^{14} \mathrm{C}\right]-\alpha$-Methyl-D-glucoside $(200 \mathrm{mCi} / \mathrm{mmole})$ and $\left[2,3-{ }^{14} \mathrm{C}\right]$ 
maleic anhydride $(30 \mathrm{mCi} / \mathrm{mmole})$ were obtained from Amersham/Searle Corp., Arlington Heights, IL. Unlabeled substrates purchased from commercial sources were of the highest purity available.

The volume of "trapped medium" in the pellet was established according to the method of Burg and Orloff (5) using carboxyl ${ }^{14} \mathrm{C}$-labeled inulin obtained from New England Nuclear. The volume of intracellular water was taken as the difference between total tissue water, determined by overnight dessication and the volume of trapped medium. The intracellular concentrations of sodium and potassium were determined according to the flame photometry method of Schwartzman et al. (23) after incubating the tubule preparations for $1 \mathrm{hr}$ with and without $6 \mathrm{mM}$ maleic acid.

\section{DETERMINATION OF PURITY OF ${ }^{14} \mathrm{C}$-LABELED MALEIC ACID}

Purity of the radioactive maleic acid was confirmed by gas chromatography of its trimethylsilyl derivative using a PerkinElmer model 3920 gas chromatograph. ${ }^{14} \mathrm{C}$-Labeled and unlabeled maleic acid as carrier were derivatized and injected at a port temperature of $320^{\circ}$ onto a 6 -foot glass column with a $0.4 \mathrm{~mm}$ diameter containing $3 \%$ OV-1 on $100 / 120$ Gas Chrom Q. The program was isothermal at $120^{\circ}$ for $4 \mathrm{~min}$, increasing thereafter to $250^{\circ}$ at a rate of $4^{\circ} / \mathrm{min}$. Peaks were collected in glass Pasteur pipetes packed in dry ice and washed through with $10 \mathrm{ml}$ of phosphor-ethanol. Radioactive material was confined exclusively to the maleic acid peak, and no other compounds could be detected as impurities.

\section{DETERMINATION OF ${ }^{14} \mathrm{CO}_{2}$ EVOLUTION}

Metabolic studies were carried out in reaction vessels (Bolab, Inc., Derry, NH) with a center well. Samples of newborn or adult tubules were placed in the center well with $6 \mathrm{mM}{ }^{14} \mathrm{C}$-labeled maleic acid. One-half milliliter of hydroxide of Hyamine [ $p$-(diisobutyl-cresoxyethoxyethyl)dimethylbenzyl-ammonium hydroxide] was placed in the outer chamber and the vessel capped and mixed. The tubules were incubated for $30 \mathrm{~min}$ at $37^{\circ}$, after which the reaction was stopped by injection of $0.1 \mathrm{ml}$ of $0.1 \mathrm{~N} \mathrm{H}_{2} \mathrm{SO}_{4}$ through the stopper into the center well. The vessel was mixed and allowed to remain at $37^{\circ}$ for $15 \mathrm{~min}$. The Hyamine was removed and added to $10 \mathrm{ml}$ of phosphor solution for counting in a Packard liquid scintillation counter. The same procedure was followed using ${ }^{14} \mathrm{C}$-labeled D-glucose as substrate in order to show actual metabolic activity by the tubule preparations.

\section{DETERMINATION OF ENZYME ACTIVITIES}

Newborn and adult kidney tubules were prepared and incubated with or without $6 \mathrm{mM}$ maleic acid with continuous gassing with $95 \% \mathrm{O}_{2}-5 \% \mathrm{CO}_{2}$ for $60 \mathrm{~min}$ at $37^{\circ}$. The tubule suspensions were centrifuged for $10 \mathrm{~min}$ at $33,000 \times g$ in a Sorvall $\mathrm{RC} 2 \mathrm{~B}$ refrigerated centrifuge. The KRB buffer was removed and the pellets were resuspended in either sodium-free $0.05 \mathrm{M}$ Tris buffer containing $0.25 \mathrm{M}$ sucrose, $\mathrm{pH} 6.8$, or in distilled water and homogenized in a glass homogenizer with a Teflon pestle. Maleic acid was added during resuspension to maintain its concentration at $6 \mathrm{mM}$, since transport effects of maleic acid have been shown to be reversible $(17,18)$.

The suspensions were assayed for $\mathrm{Na}^{+}-\mathrm{K}^{+}$-ATPase activity according to the method of Kinsolving et al. (9) This enzyme is localized at the antiluminal aspect of the tubular cell for which it serves as a marker (8). Alkaline phosphatase (25), leucine aminopeptidase (7), and $\gamma$-glutamyltranspeptidase (6), marker enzymes for the brush border, were determined by standard assay methods using tubules resuspended in distilled water or $6 \mathrm{mM}$ maleic acid immediately after homogenization. Protein content of the tubule suspensions was determined according to the method of Lowry et al. (11).

\section{RESULTS}

\section{EFFECT OF MALEIC ACID ON SUGAR AND AMINO ACID UPTAKE}

Uptake of $\alpha$-methyl-D-glucoside by the newborn tubule is both active and saturable (20). Figure 1A shows that the newborn tubule accumulates substrate at a slower rate and achieves a steady state at a lower intracellular concentration. By the end of the first week of life, initial uptake rates and steady state levels comparable to those of the adult have been achieved. Figure 1B illustrates that, although the effects of $6 \mathrm{mM}$ maleic acid on transport of $\alpha$ methyl-D-glucoside become significant by 7 days of age, its max-
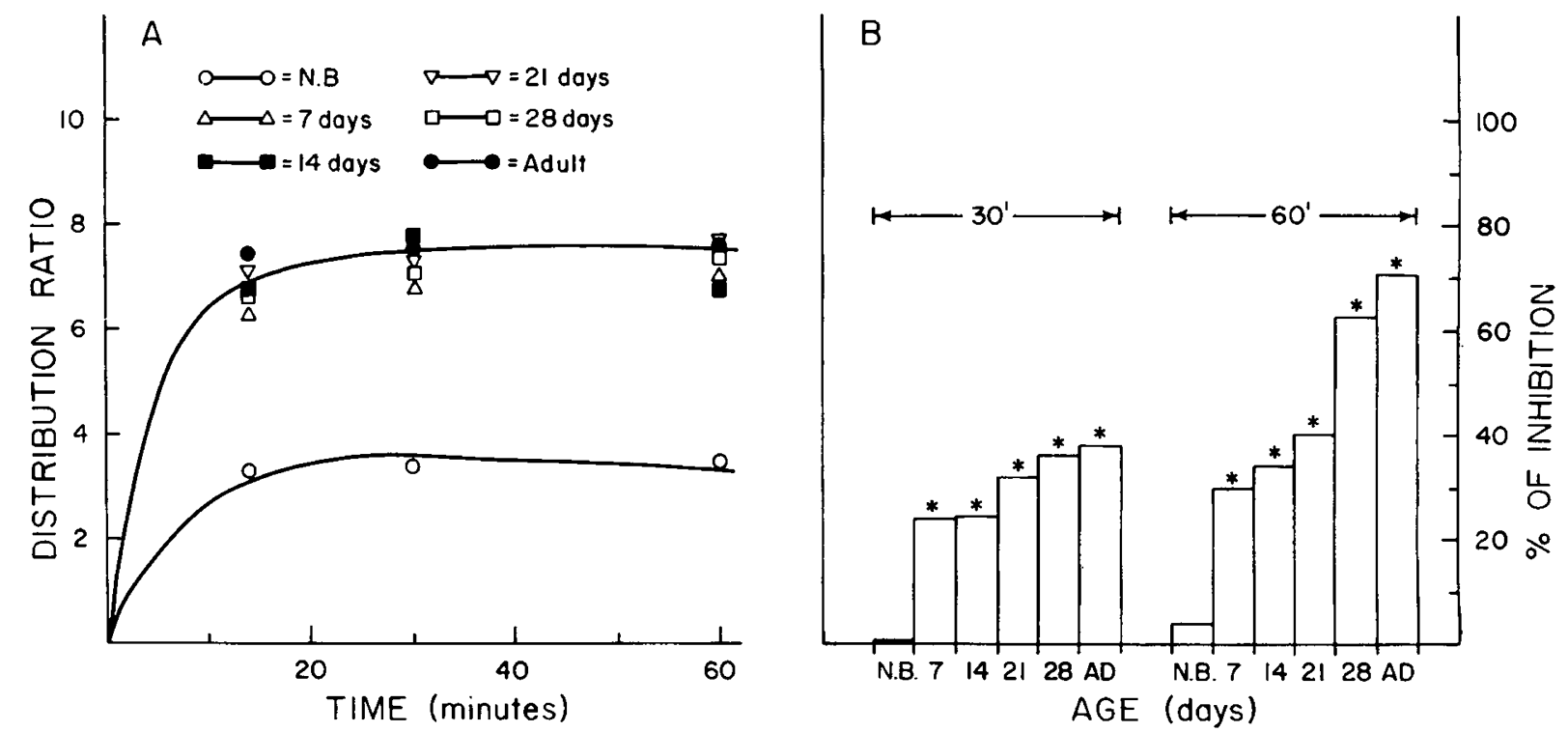

Fig. 1. $A$, Age-related $\alpha$-methyl-D-glucoside uptake; $B$, its inhibition by $6 \mathrm{mM}$ maleic acid. Tubules were isolated by the methods detailed in the text from at least two litters (20-60 animals) of rats of ages less than $72 \mathrm{hr}, 7$ days, 14 days, 21 days, 28 days, and $150-200 \mathrm{~g}$ adults. Substrate concentration in all cases was $2 \mathrm{mM}$, containing 0.1 microcurie of labeled material $/ \mathrm{ml}$ of tubule suspension. Maleic acid-treated preparations were run in parallel with the control curves shown for each age. Each data point represents the mean of at least three determinations. Distribution ratio is defined as the ratio of $\mathrm{cpm} / \mathrm{ml}$ intracellular fluid to $\mathrm{cpm} / \mathrm{ml}$ extracellular fluid (or "trapped medium space"). ${ }^{*}=$ different from control value $p<0.05$. 

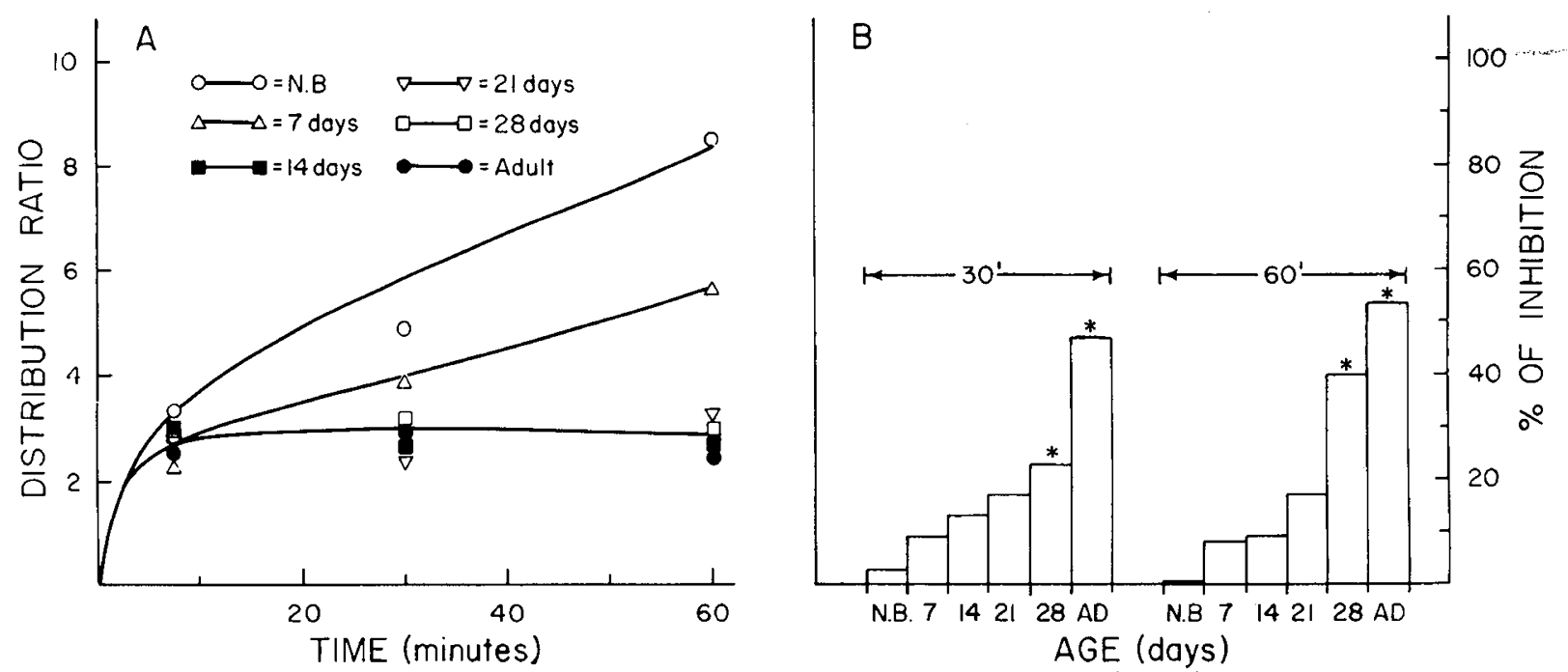

Fig. 2. $A$, Age-related $\alpha$-aminoisobutyric acid uptake; $B$, its inhibition by $6 \mathrm{mM}$ maleic acid. Amino acid concentration in all cases was $0.065 \mathrm{mM}$, containing 0.1 microcurie of labeled material $/ \mathrm{ml}$ of tubule suspension. Conditions were the same as those detailed in the text and legend for Figure 1 . Each point represents the mean of at least three experiments. ${ }^{*}=$ different from control value $P<0.05$.

imal effect is not seen until 28 days. Increased concentrations of maleic acid up to $12 \mathrm{mM}$ do not alter either the levels of substrate accumulation shown or the initial rate of uptake in the newborn.

Uptake of neutral amino acids, for which $\alpha$-aminoisobutyric acid serves as a model, is similarly active and saturable in the newborn renal cortical cell (20). Figure $2 \mathrm{~A}$ shows that the initial rate of $\alpha$-aminoisobutyric acid uptake by the isolated tubule is identical in all age groups. Beyond $15 \mathrm{~min}$ of incubation, intracellular accumulation of substrate by the newborn tubule continues. This is seen to a lesser degree at 7 days, and by 14 days the adult pattern of uptake is achieved. These observations are consistent with previous data regarding the development of neutral amino acid transport in rat kidney, which show an increased rate of efflux with maturation (20). Figure $2 \mathrm{~B}$ illustrates that $6 \mathrm{mM}$ maleic acid does not cause a significant decrease in net uptake of $\alpha$-aminoisobutyric acid until 28 days of age, although the adult transport pattern emerges by the second week of life.

\section{UPTAKE AND METABOLISM OF $\left[2,3,-{ }^{14} \mathrm{C}\right]$ MALEIC ACID}

The uptake and metabolism of ${ }^{14} \mathrm{C}$-labeled maleic acid was studied in order to determine whether the effects of this substance on newborn and adult transport processes are due to differences in handling of the inhibitor molecule. There is no concentrative uptake of maleic acid at $6 \mathrm{mM}$ in either the newborn or adult tubule (Fig. 3). However, uptake studies performed at $0^{\circ}$ without prolonged incubation demonstrate a significant degree of tubuleassociated radioactivity, probably representing binding to the cell membrane. Over time, even at $0^{\circ}$, maleic acid penetrates the cells, achieving a distribution ratio of about one in both newborn and adult tubules and thereby suggesting entry by simple diffusion.

Measurements of ${ }^{14} \mathrm{CO}_{2}$ evolved from newborn and adult tubules in the presence of chromatographically pure ${ }^{14} \mathrm{C}$-labeled maleic acid at a concentration of $6 \mathrm{mM}$ reveals no metabolism of the substrate by either preparation, although the same preparations under the same conditions metabolize labeled glucose at a significant rate.

\section{EFFECT OF MALEIC ACID ON MEMBRANE-ASSOCIATED ENZYMES}

After studying the uptake and metabolic fate of maleic acid in the newborn and adult tubule, we investigated its effect on tubular membrane-associated enzymes. Six millimolar maleic acid has no significant effect on the specific activities of any of the four enzymes assayed (Table 1). The specific activities of alkaline

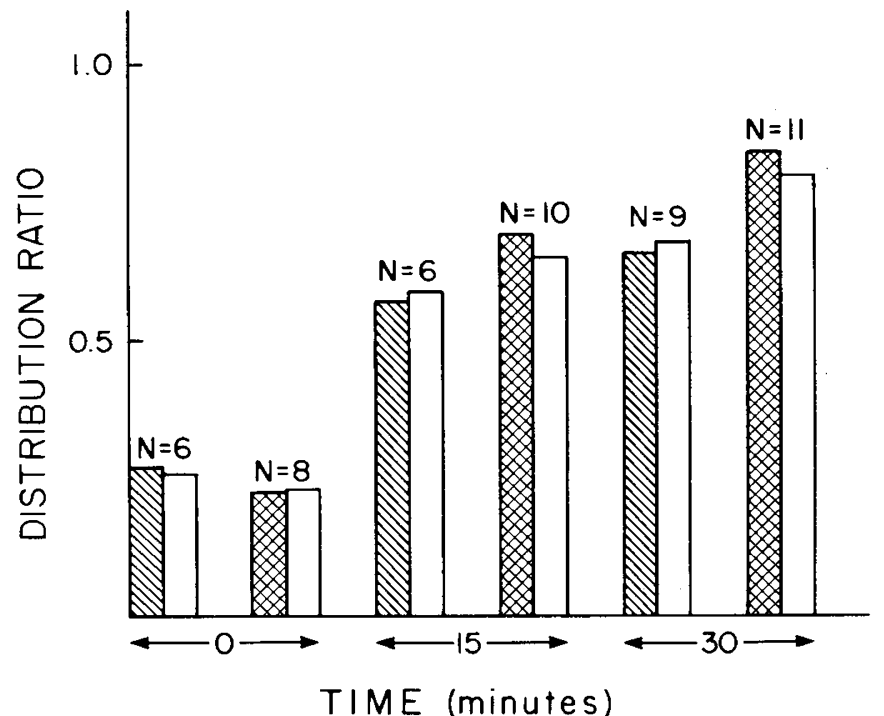

Fig. 3. Penetration of $6 \mathrm{mM}\left[2,3,{ }^{14} \mathrm{C}\right]$ maleic acid into isolated adult and newborn tubules. Tubules were prepared from adult (cross-hatched bars) and from newborn (single-hatched bars) animals and studied under the same conditions as those used for uptake studies using sugar and amino acid. Parallel studies were carried out at $0^{\circ}$, which yielded results shown by open bars. Adult and newborn studies were carried out in parallel with the number of data points shown above the bars for each time point.

phosphatase and $\mathrm{Na}^{+}-\mathrm{K}^{+}$-ATPase are higher in the adult; findings that are in agreement with the data of Goldmann et al. (7), who studied these enzymes in isolated rat renal brush border membranes. Leucine aminopeptidase and $\gamma$-glutamyltranspeptidase, however, did not show the same increase with age. This may be due to the differences in the isolation procedures for the two preparations.

The presence of $6 \mathrm{mM}$ maleic acid during the incubation of both newborn and adult tubules has no inhibitory effect on the specific activity of $\mathrm{Na}^{+}-\mathrm{K}^{+}$-ATPase and has no effect on the intracellular concentrations of sodium and potassium measured both at the beginning and the end of a 1-hr incubation. The same assay procedure carried out on tubules exposed to sucrose-Tris

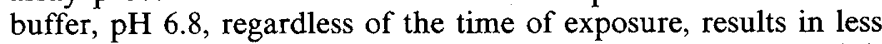
than one-half of the control activities in both newborn and adult 
Table 1. Summary of effects of maleic acid on membrane-associated enzymes ${ }^{1}$

\begin{tabular}{|c|c|c|c|c|c|c|c|c|}
\hline & \multicolumn{4}{|c|}{ Newborn } & \multicolumn{4}{|c|}{ Adult } \\
\hline & Control & $\mathrm{N}$ & $\begin{array}{c}6 \mathrm{mM} \text { Maleic } \\
\text { acid }\end{array}$ & $\mathrm{N}$ & Control & $\mathrm{N}$ & $6 \mathrm{mM}$ Maleic acid & $\mathrm{N}$ \\
\hline $\begin{array}{l}\left(\mathrm{Na}^{+}+\mathrm{K}^{+}\right) \text {ATPase } \\
\quad\left(\mu \text { mole } \mathrm{P}_{\mathrm{i}} \text { liberated } / \mathrm{mg} \text { protein } / \mathrm{hr}\right)\end{array}$ & $\begin{array}{c}5.59 \pm 0.56 \\
(3.62 \pm 0.38)^{2}\end{array}$ & $\begin{array}{l}4 \\
4\end{array}$ & $\begin{array}{c}5.71 \pm 0.97 \\
(4.03 \pm 0.28)\end{array}$ & $\begin{array}{l}4 \\
4\end{array}$ & $\begin{array}{l}10.61 \pm 0.70 \\
(3.82 \pm 0.41)\end{array}$ & $\begin{array}{l}6 \\
4\end{array}$ & $\begin{array}{c}8.16 \pm 1.26 \\
(2.34 \pm 0.23)\end{array}$ & $\begin{array}{l}5 \\
4\end{array}$ \\
\hline $\begin{array}{l}\text { Alkaline phosphatase } \\
\text { (Sigma units/mg protein/30 min) }\end{array}$ & $73.69 \pm 7.31$ & 7 & $89.89 \pm 10.82$ & 7 & $151.92 \pm 13.03$ & 9 & $144.48 \pm 6.34$ & 9 \\
\hline $\begin{array}{l}\gamma \text {-glutamyltranspeptidase } \\
(\mu \mathrm{mole} / \mathrm{mg} \text { protein } / \mathrm{min})\end{array}$ & $0.28 \pm 0.05$ & 4 & $0.37 \pm 0.04$ & 4 & $0.31 \pm 0.03$ & 9 & $0.31 \pm 0.03$ & 8 \\
\hline $\begin{array}{l}\text { Leucine aminopeptidase } \\
(\mu \mathrm{mole} / \mathrm{mg} \text { protein } / \mathrm{hr})\end{array}$ & $4.47 \pm 0.54$ & 5 & $5.09 \pm 0.35$ & 5 & $5.01 \pm 0.68$ & 8 & $5.11 \pm 0.34$ & 8 \\
\hline
\end{tabular}

( $\mu \mathrm{mole} / \mathrm{mg}$ protein $/ \mathrm{hr}$ )

1 Newborn and adult tubule preparations were incubated for $60 \mathrm{~min}$ at $37^{\circ}$ with and without $6 \mathrm{mM}$ maleic acid and then assayed for enzyme activity. $\mathrm{N}$, the number of triplicate determinations of each assay. In all cases, there is no statistical significance between enzyme activities with and without 6 $\mathrm{mM}$ maleic acid, when assayed in distilled water.

${ }^{2}$ Numbers in parentheses represent values for $\mathrm{Na}^{+}-\mathrm{K}^{+}$-ATPase activity assayed in sucrose-Tris buffer with or without 6 mM maleate; in adult tubules under these conditions there is significant inhibition by maleate $(P<0.05)$.

preparations. Some degree of inhibition of $\mathrm{Na}^{+}-\mathrm{K}^{+}$-ATPase activity by $6 \mathrm{mM}$ maleic acid is seen in sucrose-Tris buffer. These observations suggest that sucrose-Tris buffer in itself causes an immediate depression of $\mathrm{Na}^{+}-\mathrm{K}^{+}$-ATPase activity in the tubule preparation.

The specific activity of $\gamma$-glutamyltranspeptidase, an enzyme postulated to be involved in amino acid transport (12), is similarly unaffected by $6 \mathrm{mM}$ maleic acid. The specific activity of the enzyme was measured with and without the addition of glycylglycine acceptor to separate its known transpeptidation and hydrolytic actions (29), and neither action appears to be significantly s.inhibited.or stimulated by $6 \mathrm{mM}$ maleic acid in either newborn or adult tubule preparations.

\section{DISCUSSION}

We have observed that transport processes for amino acids and sugars in the Sprague-Dawley rat tubule preparation develop independently over the first 4 weeks of life. The adult transport pattern for $0.065 \mathrm{mM} \alpha$-aminoisobutyric acid in the tubule appears at 14 days, whereas Segal et al. (24) observed that the adult pattern in kidney slices appears between 23 and 42 days. The adult transport pattern for $2 \mathrm{mM} \alpha$-methyl-D-glucoside appears by the end of the first week in our preparation but only after the second week in the slice.

Roth et al. (20) have established the validity of the use of the tubule preparation for the study of glycine transport, showing that initial uptake rates for newborn and adult are identical as they are in the slice. The $\mathrm{V}_{\max }$ values for glycine transport by tubules are considerably higher than those observed in cortical slices from rats of the same age, suggesting a greater efficiency of transport in the tubule model (19). This increased efficiency may be reflected in a greater sensitivity to change and may explain the earlier appearance of mature transport systems for amino acid and sugar analogs in the tubule preparation.

Although Segal et al. (24) have demonstrated the presence of a rudimentary sugar transport system in the newborn cortical slice, Roth et al. (20) have shown active concentration-dependent transport of the glucose transport analog $\alpha$-methyl-D-glucoside in the newborn renal tubule in vitro. These same workers have also demonstrated concentrative uptake of this substance by newborn tubule in vivo (21). These data suggest that the cortical slice may not be-a good model for developmental studies of sugar transport.

In the adult renal tubule $6 \mathrm{mM}$ maleic acid has been shown to increase the efflux rate of $\alpha$-methyl-D-glucoside by $100 \%$ between 15 and $30 \mathrm{~min}$, thereafter decreasing influx as well (18). The data in Figure 1B showing the maleic acid effect on $\alpha$-methyl-D-glucoside transport at 30 and 60 min could be interpreted as reflecting an increased efflux at $30 \mathrm{~min}$, and the net of increased efflux and decreased influx at $60 \mathrm{~min}$. Therefore, the increase in maleic acid- induced efflux at $30 \mathrm{~min}$ appears within the first week of life while the major effect of maleic acid on influx at $60 \mathrm{~min}$ appears between 21 and 28 days of age.

Rosenberg et al. (17) have shown that maleic acid decreases the steady-state intracellular amino acid pool in adult rat cortical slices by accelerating efflux and to a lesser degree by retarding influx. Our data can be interpreted similarly, suggesting that the significant maleic acid-induced decrease in intracellular accumulation of $\alpha$-aminoisobutyric acid by the 28-day-old and adult tubule at $30 \mathrm{~min}$ is the result of increased efflux and at $60 \mathrm{~min}$ the result of both increased efflux and decreased influx.

We have shown that maleic acid inhibits both the transport of $\alpha$-aminoisobutyric acid and $\alpha$-methyl-D-glucoside in the adult rat kidney tubule, findings which confirm earlier observations for $\alpha$ aminoisobutyric acid uptake in the cortical slice (17) and for $\alpha$ methyl-D-glucoside in the adult tubule (18). Significant alterations in $\alpha$-methyl-D-glucoside uptake induced by maleic acid appear by 7 days of age and increase during the first 4 weeks of life, achieving adult levels 3 weeks after maturation of the transport system for sugars. However, significant changes in the uptake of $\alpha$-aminoisobutyric acid do not appear until 28 days of age, 2 weeks after maturation of the transport system for neutral amino acids. These observations suggest that the newborn tubule is relatively insensitive to the inhibitory effects of maleic acid and that the effects of this compound on sugar and amino acid transport processes are separate and independent of their developmental patterns.

The renal tubular dysfunction induced in animals by injection of maleic acid has been used since 1954 as an experimental model for the human Fanconi syndrome (24). The primary effect of this compound has been shown to be one of increasing efflux of amino acids $(2-4,17)$ and sugars (18), but the molecular basis for this action on the proximal tubule remains obscure. Although the human Fanconi syndrome is frequently observed in inherited metabolic diseases seen in infants and children, there has been no previous in vivo or in vitro work detailing the effects of maleic acid on immature animals. Based upon previous work characterizing sugar and amino acid transport in the newborn rat renal tubule (20) and the effect of maleic acid on the kinetic parameters of sugar transport in the adult rat renal tubule (18), application of these techniques to study of the effects of maleic acid on transport in the newborn assumes added importance.

Currently accepted theory accounting for the intracellular concentration of sugars and amino acids across the renal cortical brush border, rests upon the ability of the sodium pump or membrane $\mathrm{Na}^{+}-\mathrm{K}^{+}$-ATPase to generate an electrochemical gradient by excluding $\mathrm{Na}^{+}$ions from the interior of the cell. This theory led Kramer and Gonick (10) to investigate the effects of maleic acid on rat renal cortical $\mathrm{Na}^{+}-\mathrm{K}^{+}$-ATPase. Their observations were consistent with the possibility that maleic acid-induced inhibition of the sodium pump mechanism causes reduction in the 
rate of entry of filtered sugars and amino acids, leading to the glycosuria and aminoaciduria seen in the maleic acid-treated rat. The fact that maleic acid increases efflux and exerts a noncompetitive inhibitory effect on the transport of $\alpha$-methyl-D-glucoside by adult renal tubules (18) would seem to support this hypothesis. Therefore, when the observation was made that maleic acid had no effect on $\alpha$-methyl-D-glucoside transport by the newborn tubule, an investigation of the action of maleic acid on membrane $\mathrm{Na}^{+}-\mathrm{K}^{+}$-ATPase in the newborn became mandatory.

Goldmann et al. (7) have demonstrated an increase in the specific activity of $\mathrm{Na}^{+}-\mathrm{K}^{+}$-ATPase in rat renal cortical homogenates during maturation. Our present observations support their conclusion that this maturational change is largely quantitative, since in neither newborn nor adult tubule preparations are we able to demonstrate inhibition of this enzyme by maleic acid. Maleic acid inhibition of sugar transport only in the adult but resistance of membrane-associated $\mathrm{Na}^{+}-\mathrm{K}^{+}$-ATPase to this compound in both age groups leads to the conclusion that present concepts of renal sugar transport are incomplete.

The question of maleic acid inhibition of $\mathrm{Na}^{+}-\mathrm{K}^{+}$-ATPase and its relation to transport processes is further complicated by methodological problems. Kramer and Gonick (10) have shown that maleic acid inhibits renal $\mathrm{Na}^{+}-\mathrm{K}^{+}$-ATPase when administered to rats in vivo as well as when added to the enzyme assay in vitro. They achieved in vivo inhibition by injecting animals with 1.5 or 9.0 mmoles of maleic acid $/ \mathrm{kg}$ of body weight. Since maleic acid penetrates only renal cortical cells to any significant degree (17), it appears that the kidneys of their animals were exposed to 40 or 50 times as much maleic acid as our isolated tubules. They also found that these large doses produced alterations in the fine structure of the proximal tubule in vivo (15), but earlier work from this laboratory showed that $6 \mathrm{mM}$ maleic acid had no effect on tubule ultrastructure while producing significant perturbations in $\alpha$-methyl-D-glucoside transport in vitro (18). Paradoxically, they achieved in vitro inhibition of $\mathrm{Na}^{+}-\mathrm{K}^{+}$-ATPase in crude renal cortex homogenates with very small concentrations of maleic acid up to $1 \mathrm{mM}$. We are unable to demonstrate inhibition of $\mathrm{Na}^{+}-\mathrm{K}^{+}-$ ATPase in tubules incubated in KRB buffer containing $6 \mathrm{mM}$ maleic acid and resuspended in distilled water containing the same concentration of maleate, and find no effect of maleic acid on intracellular concentrations of sodium and potassium. Kramer and Gonick prepared their tissue in sucrose-Tris buffer, which in our hands inhibits the activity of the enzyme (Table 1) and may further facilitate the inhibition by maleic acid that they observed.

The relation of $\mathrm{Na}^{+}-\mathrm{K}^{+}$-ATPase activity to transport of sugars and amino acids remains unclear. Wapnir et al. (30) found that intraperitoneal injection of maleic acid inhibits jejunal $\mathrm{Na}^{+}-\mathrm{K}^{+}$ATPase by one-third, as well as sodium transport, but has no effect on gut transport of glucose or amino acids. Because maleic acid penetration of gut tissue is approximately $20 \%$ that of kidney, they used enormous doses to achieve an effect. Rea and Segal (13) have shown that maleic acid causes a marked depression of intracellular levels of ATP in adult rat kidney slices, but has a disparately modest effect on the steady-state levels of $\alpha$-aminoisobutyric acid achieved in transport experiments. These findings as well as our own suggest that the conclusions drawn by Kramer and Gonick based upon their enzyme data may have no definite functional correlation.

Meister (12) has postulated that the $\gamma$-glutamyl cycle plays a major role in the transfer of amino acids across the cell membrane. A key enzyme in the translocation is thought to be $\gamma$-glutamyltranspeptidase, which has both transpeptidation and hydrolytic functions (29). Tate and Meister (28) have purified this enzyme and have demonstrated that $50 \mathrm{mM}$ maleic acid stimulates its hydrolytic function but inhibits transpeptidation. Our data in the intact tubule, however, reveal no such stimulation or inhibition of either enzyme function by $6 \mathrm{mM}$ maleic acid, a concentration which clearly affects sugar and amino acid transport in the adult tubule. Therefore, it seems probable that the $\gamma$-glutamyl cycle does not play a major role in maleic acid-induced transport inhibition.

Our data cannot rule out subtle differences in membrane struc- ture between the newborn and adult rat renal tubule to explain their different transport responses to maleic acid, but our observations regarding the handling of labeled maleic acid by the tubular cell and the lack of inhibition of membrane-associated enzymes by this compound do not support this possibility. Maleic acid binds to the membrane and diffuses into the cell to the same extent in both age groups. Neither newborn nor adult tubule preparations metabolize maleic acid to carbon dioxide, and therefore probably do not convert this compound to malate as has been shown in the rabbit (27).

Others have reported that levels of cystine in renal tissue from aborted human fetuses with cystinosis are as high as levels in kidneys removed at the time of renal transplant in children from $8-10$ years old $(22,26)$. This evidence casts serious doubt on the notion that the Fanconi syndrome in cystinosis is the result of increasing accumulation of cystine in the renal cortical cell over time. The present report suggests that the toxic effects of substances like maleic acid or cystine may not exert deleterious effects on renal transport until a certain point in the maturation of transport systems. This would explain the clinical observation that renal function appears to be normal over the first 6 months of life in cystinosis, despite the presence of high cystine levels in the kidney.

The Fanconi syndrome may be the result of interference with or inhibition of the energy supply or linkage essential to membrane transport systems rather than a direct effect on the membrane itself. The work of Reynolds et al. (14), showing no effect of maleic acid on the transport of sugars and amino acids in the isolated rat renal brush border vesicle, would support this contention. Our studies suggest new avenues of investigation in a search for the biochemical explanation of the Fanconi syndrome seen in cystinosis and other inherited metabolic diseases.

\section{REFERENCES AND NOTES}

1. Angielsi, S., and Rogulski, J.: Effect of maleic acid on the kidney. I. Oxidation of Krebs cycle intermediates by various tissues of maleate-intoxicated rats. Acta Biochim. Pol., 9: 357 (1962).

2. Bergeron, M.: Renal amino acid accumulation in maleate-treated rats. Rev. Can. Biol, 30: 267 (1971).

3. Bergeron, M., Dubord, L., and Hausser, C.: Membrane permeability as a cause of transport defects in experimental Fanconi syndrome. J. Clin. Invest., 57 . $1181(1976)$.

4. Bergeron, M., and Vadeboncoeur, M.: Microinjections of L-leucine into tubules and peritubular capillaries of the rat. Nephron, 8: 367 (1971).

5. Burg, M. B., and Orloff, J.: Oxygen consumption and active transport in separated renal tubules. Am. J. Physiol., 203: 327 (1962).

6. Glossman, H., and Neville, D. M.: Gamma-glutamyltransferase in kidney brush border membranes. FEBS Lett., 19: 340 (1972).

7. Goldmann, D. R., Schlesinger, H., and Segal, S.: Isolation and characterization of the brush border fraction from newborn rat renal proximal tubules. Biochim. Biophys. Acta, 419: 251 (1976)

8. Heidrich, H., Kinne, R., Kinne-Saffran, E., and Hannig, K. The polarity of the proximal tubule cell in rat kidney. Different surface charges for the brushborder microvilli and plasma membranes from the basal infoldings. J. Cell Biol., 54: 232 (1972)

9. Kinsolving, C. R., Post, R. L., and Beaver, D. L.: Sodium plus potassium transport adenosine triphosphatase activity in kidney. J. Cell. Comp. Physiol., 62: 85 (1963).

10. Kramer, H. J., and Gonick, H. C.: Experimental Fanconi syndrome. I. Effect of maleic acid on renal cortical Na-K-ATPase activity and ATP levels. J. Lab. Clin. Med., 76: 799 (1970).

11. Lowry, O. H., Rosebrough, N. J., Farr, A. L., and Randall, R. J.: Protein measurement with the Folin phenol reagent. J. Biol. Chem., 193: 265 (1951)

12. Meister, A.: On the enzymology of amino acid transport. Science, 180: 33 (1973).

13. Rea, C., and Segal, S.: ATP content of rat kidney cortex slices: Relation to $\alpha-$ aminoisobutyric acid uptake. Kidney Int., 2: 101 (1972).

14. Reynolds, R., McNamara, P. D., and Segal, S.: On the maleic acid induced Fanconi syndrome: Effects on transport by isolated rat kidney brushborder membrane vesicles. Life Sci., 22: 39 (1978)

15. Rosen, V. J., Kramer, H. J., and Gonick, H. C.: Experimental Fanconi syndrome II. Effect of maleic acid on renal tubular ultrastructure. Lab. Invest., 28: 446 (1973)

16. Rosenberg, L. E., Blair, A., and Segal, S.: The transport of amino acids by rat kidney cortex slices. Biochim. Biophys. Acta, 54: 479 (1961).

17. Rosenberg, L. E., and Segal, S.: Maleic-acid induced inhibition of amino acid transport in rat kidney. Biochem. J., 92: 345 (1964).

18. Roth, K. S., Hwang, S. M., and Segal, S.: Effect of maleic acid on the kinetics of $\alpha$-methyl-D-glucoside uptake by isolated rat renal tubules. Biochim. Biophys. Acta, 426: 675 (1976)

19. Roth, K. S., Hwang, S. M., London, J. W., and Segal, S.: Ontogeny of glycine 
transport in isolated rat renal tubules. Am. J. Physiol., 233: F24l (1977)

20. Roth, K. S., Hwang, S. M., Yudkoff, M., and Segal, S.: On the transport of sugars and amino acids by newborn kidney: Use of isolated proximal tubule. Life Sci., I8: 1125 (1976).

21. Roth, K. S., Hwang, S. M., Yudkoff, M., and Segal, S.: Sugar transport in isolated newborn rat renal tubules: A possible explanation for the absence of neonatal glucosuria. Abstract presented at Society for Pediatric Research, April 1977, San Francisco, CA., p. 556.

22. Schneider, J. A., Verroust, F. M., Kroll, W. A., et al.: Prenatal diagnosis of cystinosis. N. Engl. J. Med., 290: 878 (1974).

23. Schwartzman, L., Blair, A., and Segal, S.: Effect of transport inhibitors on dibasic amino acid exchange diffusion in rat kidney cortex. Biochim. Biophys. Acta, 135: 136 (1967)

24. Segal, S., Rea, C., and Smith, I.: Separate transport systems for sugars and amino acids in developing rat kidney cortex. Proc. Natl. Acad. Sci. USA, 68: 327 (1971).

25. Sigma Technical Bulletin No. 104: The colorimetric determination of phosphatase. Sigma Chemical Co., St. Louis, MO. (1963)

26. States, B., Blazer, B., Harris, D., and Segal, S.: Prenatal diagnosis of cystinosis. J. Pediatr., 87: 558 (1975).
27. Taggart, J. V., Angielski, S., and Morell, H.: Complete oxidation of maleic acid via $\mathrm{D}(+)$ maleate in kidney. Biochim. Biophys. Acta, 58: 141 (1962).

28. Tate, S. S., and Meister, A.: Identity of maleate-stimulated glutaminase with gamma-glutamyl transpeptidase in rat kidney. J. Biol. Chem., 250: 4619 (1975).

29. Thompson, G. A., and Meister, A.: Hydrolysis and transfer reactions catalyzed by gamma-glutamyl transpeptidase; evidence for separate substrate sites and for high-affinity of $\mathrm{L}$-cystine. Biochem. Biophys. Res. Commun., 71: 32 (1976).

30. Wapnir, R. A., Exeni R. A., McVicar, M., DeRosas, F. J., and Lifshitz, F.: Inhibition of sodium intestinal transport and mucosal $\left(\mathrm{Na}^{+}-\mathrm{K}^{+}\right)$-ATPase in experimental Fanconi syndrome. Proc. Soc. Exp. Biol. Med., 150: 317 (1975).

31. The authors gratefully acknowledge the technical assistance of Mr. Thomas Langfitt.

32. This research was supported by Grant AM 10894 from the National Institutes of Health, Bethesda, Maryland.

33. Dr. Roth is the recipient of the Daland Award of the American Philosophical Society.

34. Dr. Roth's address is Children's Hospital of Philadelphia, 34th Street and Civic Center Boulevard, Philadelphia, Pennsylvania 19104

35. Received for publication November 22, 1977.

36. Accepted for publication February 8, 1978. 